\title{
An International Perspective on Graduate Education in Physical Oceanography
}

\author{
Holger Brix', James L. Hench², Helen L. Johnson ${ }^{3}$, T.M. Shaun Johnston", Jeff A. Polton ${ }^{5}$, \\ Moninya Roughan ${ }^{6}$, Pierre Testor ${ }^{7}$
}

Institute of Geophysics and Planetary Physics, University of California, Los Angeles, USA.
${ }^{2}$ Institute of Marine Sciences, University of North Carolina at Chapel Hill, USA.
${ }^{3}$ School of Earth and Ocean Sciences, University of Victoria, Canada.
${ }^{4}$ Department of Oceanography, University of Hawaii, Honolulu, USA.
${ }^{5}$ Department of Meteorology, University of Reading, UK.
${ }^{6}$ Scripps Institution of Oceanography, University of California, San Diego, USA.
'Laboratoire d'Océanographie Dynamique et de Climatologie, Univ. P. et M. Curie, Paris, France.

During the inaugural Physical Oceanography Dissertation Symposium in June 2002 we found that the graduate school experience varied markedly amongst the 20 international participants. The diversity of backgrounds led to lively discussion about the differences between physical oceanography programs. Here we review the length, content, and quality of education for graduate programs in Australia, France, Germany, the UK, and the U.S. We also comment on the financial, social, and scientific status of graduate students in these countries. Graduate programs in physical oceanography face the challenge of introducing students to the wide range of tools and techniques which define the field, ranging from observational work and remote sensing, through dynamical theory and laboratory experiments, to numerical modeling. While individual character largely determines the success of the Ph.D. experience, a graduate education in physical oceanography should include the following factors to best serve students in their future career: solid mentorship, regular department level progress checks, course work, summer schools, field work, practice in communication skills, scientific and social integration, international exchange, and stable and sufficient funding. We propose a model four year physical oceanography graduate degree structure, distilled from the best aspects of international physical oceanography programs.

\section{Introduction}

For one week during June 2002, 20 young scientists of 13 different nationalities, who worked on their Ph.D.s in 7 different countries, met at the first Physical Oceanography Dissertation Symposium (PODS I) in Breckenridge, Colorado. The goals of the meeting were to discuss the current and future state of the field, to present research, to gain insight into the funding process, and to meet future colleagues. This setting yielded a unique international cross-pollination of recent Ph.D.s and led to a number of lively conversations about the differences between physical oceanography programs. Several questions arose:

1. How do physical oceanography programs differ internationally?

2. What are the most positive aspects of each?

3. Can we extract and combine the best parts of each program to suggest improvements in how physical oceanographers are educated?

Physical oceanography is defined by a unique blend of theoretical work, laboratory experiments, field observations, remote sensing and numerical modeling. It will, by its very nature, produce Ph.D. graduates who differ widely in terms of interests and skills. During the meeting however, it became apparent that the graduate school experience also varied markedly amongst the attendees in terms of funding, duration, mentorship, and content. In this paper we examine critically these differences, extract the positive aspects, and create recommendations for a graduate experience, which better prepares a student for a career in physical oceanography. Whilst we recognize the importance of a Masters level graduate education, the focus throughout is on Ph.D. programs.

A recent review by Nyquist (2002) indicates there are a number of broader calls for reforming Ph.D. education in the U.S. However, none of these proposals is being led by the marine sciences community (McManus, 2002b). Herein, we aim to provoke discussion on the way physical oceanographers specifically are educated. 


\section{Table 1 \\ Prerequisites, duration, and coursework}

Pre modeling requisites, duration and coursework required for Ph.D.s in various countries. Also shown are the total duration of university education in each case, together with the minimum total amount of taught coursework. All figures are in years. Note that requirements differ between universities/institutes within each country. BSc $=$ Bachelor of Science, Hons $=$ Honors, MSc $=$ Master of Science, Bac = Baccalaureate, DEA = Diplome d'Etude Approfondies (Advanced Studies Diploma).

\begin{tabular}{l|ll|l|l|l|l} 
Country & Prerequisites & & $\begin{array}{l}\text { Ph.D. } \\
\text { duration }\end{array}$ & $\begin{array}{l}\text { Ph.D. } \\
\text { courses } \\
\text { education }\end{array}$ & $\begin{array}{l}\text { Total } \\
\text { university } \\
\text { courses }\end{array}$ & $\begin{array}{l}\text { Total } \\
\text { compulsory }\end{array}$ \\
\hline Australia & $\begin{array}{l}\text { BSc (Hons) } \\
\text { or BSc + MSc }\end{array}$ & $\begin{array}{l}4 \\
(3+2)\end{array}$ & $3-3.5$ & none & $7-8.5$ & 3 \\
\hline France & Bac + DEA & 5 & 3 & 2 & 8 & 7 \\
\hline Germany & Diplom & $5-6$ & $3-6$ & none & $8-12$ & 5 \\
\hline UK & $\begin{array}{l}\text { BSc (Hons) } \\
\text { often additional MSc }\end{array}$ & $3-4$ & $3-4$ & $0-1$ & $6-9$ & 3 \\
\hline US & BSc & 4 & $3-6$ & $1.5-2$ & $7-10$ & 5.5
\end{tabular}

* 4 th year not generally funded

The paper is organized as follows. In Section 2 we identify the disparities which currently exist between Ph.D. programs internationally. Section 3 addresses the issue of mentorship which is so crucial to a successful Ph.D. education. In Section 4 the key elements of a physical oceanography graduate education are considered, and in Section 5 recommendations are given for a model Ph.D. program.

\section{International Differences}

The time taken to complete a Ph.D., based on the experiences of PODS participants in Australia, France, Germany, Japan, the UK and the U.S., varied from 3-7 years, with an average of 4 years. This was considerably shorter than the mean time of 5.3 years spent working towards a marine sciences Ph.D. in U.S. institutions (Schoedinger, 1998). In Germany and the U.S., where Ph.D.s are generally longest, graduate students are considered to be employees of their advisor/institution, and usually have the opportunity to broaden their physical oceanography background by undertaking work unrelated to their dissertation. In contrast, a Ph.D. in the UK, France or Australia is viewed solely as continued education and is highly focused on the final product, with little remuneration. The funding pressure provides a strong motivation for minimizing the time spent at graduate school.

As well as its level, the duration of funding also varies between Ph.D. programs. A survey of conference participants indicated that in the UK and France the funding is strictly limited to 3 years, whilst in Australia there is money for up to 3.5 years, and in Germany and the U.S. there is sometimes support for up to 6 years depending on the institution. In general the shorter programs offer less money, motivating students to finish quickly.

Exposure to teaching also varies between graduate programs internationally. Only in the U.S. is teaching a common requirement for graduation, although the opportunity to teach often exists elsewhere.

Part of the reason for the difference in length of physical oceanography Ph.D.s lies in the prerequisites for graduate programs (Table 1). In Australia and the UK either a first class Honours degree or a 2 year Masters (usually by coursework) is generally required, whilst in Germany and France a 5 year Diplom (including undergraduate studies) is a prerequisite. In the U.S. students usually enter a Ph.D. program with just a broad undergraduate degree. Coursework represents a much larger part of a physical oceanography graduate education in the U.S. than elsewhere, with courses in the first year providing the necessary background. As an attempt to compare international programs fairly despite the substantial differences in qualifications with which students enter higher education (OECD, 2001), Table 1 also shows the total number of years of undergraduate plus graduate study. It reveals considerable variation in this total duration of academic education (6 to 12 years), as well as in the number of years of compulsory taught courses (3 to 7 years). 
Perhaps another reason for the difference between physical oceanography programs internationally stems from their historical objectives. As Farrington (2001) points out, the focus of most U.S. physical oceanography programs during the 1960s and 1970s was to provide for the desired expansion of faculty, and to increase the physical oceanography presence at what were previously marine biological institutions. U.S. graduate programs have therefore historically been designed to produce high-level faculty. A survey of Scripps graduates over the last 20 years demonstrates that, for this institute at least, the majority of Ph.D. graduates still follow academic career paths (Table 2). $65 \%$ of all Ph.D. graduates in the survey took jobs in educational institutions, and of the $12 \%$ employed in the private sector only 3 positions were filled over the last 10 years. Compared to the results of a survey across all ocean science disciplines in the U.S. (Schoedinger and Gordon 2002) the number of physical oceanographers employed in educational institutions is high, with fewer graduates employed privately or by government agencies.

Nowell (2000) makes further comparisons between the career paths of ocean scientists and physicists. Only $36 \%$ of U.S. Ph.D. recipients in physics follow academic career paths. He notes that oceanography graduate programs in the U.S. often resemble research appren-

\section{Table 2}

Positions taken by graduates of Scripps Institution of Oceanography over the last 20 years. Also shown are results from Schoedinger and Gordon (2002) who surveyed graduates across U.S. ocean sciences in general.

\begin{tabular}{l|c|c|c|c} 
& \multicolumn{2}{|c|}{ Ocean Sciences' } & \multicolumn{2}{c}{ Physical Oceanography ${ }^{2}$} \\
\hline Post-graduation employment & Masters & Ph.D. & Masters & Ph.D. \\
\hline Educational institution & $12 \%$ & $50 \%$ & $12 \%$ & $65 \%$ \\
\hline Government agency & $20 \%$ & $15 \%$ & $3 \%$ & $10 \%$ \\
\hline Private sector & $22 \%$ & $17 \%$ & $24 \%$ & $12 \%$ \\
\hline Employment unknown & $39 \%$ & $18 \%$ & $61 \%$ & $13 \%$ \\
\hline Enrolled in other university & $7 \%$ & N/A & - & N/A
\end{tabular}

${ }^{1}$ Survey of 485 Masters and $252 \mathrm{Ph} . \mathrm{D}$. recipients in Ocean Sciences who graduated in the U.S. between July 2000 and June 2001. (Schoedinger and Gordon 2002)

${ }^{2}$ Survey of 34 Masters and 69 Ph.D. recipients in Physical Oceanography who graduated from the Scripps Institution of Oceanography (University of California San Diego) during 1971-2002.

${ }^{3}$ May include international students who left the U.S.. ticeships. Outside the U.S., where countries have been less able to absorb Ph.D. graduates into faculty positions, there has not been such an explicit focus on faculty training. Nowell (2000) suggests that perhaps it is more appropriate today to aim to produce scientifically literate and numerically adept graduates, with an awareness of environmental concepts, who then enter a wide range of careers. In fact, career choices for graduates in physical oceanography, in all countries, are broad, and include opportunities in government laboratories, insurance companies, investment banks, consulting companies, and the offshore oil and gas industry, although the number of positions outside of academia is small.

This issue of the historical objectives of U.S. graduate programs is also relevant to Section 4, where the coursework element of a model graduate program is discussed. In this paper we focus on preparation for an academic career, although the components of a model program discussed in Section 4 and the recommendations made in Section 5 are equally relevant to other career paths.

In summary, there appears to be a split between "fast-track" and "long-track" Ph.D. programs. "Fasttrack" graduate programs in Australia and the UK generally last 3-4 years, include minimal coursework and are highly focused on a specific project (usually proposed by an advisor). Whilst discussions with senior physical oceanographers indicate that these "fasttrack" Ph.D.s generally produce the same quality of dissertation as "long-track" Ph.D.s undertaken in U.S. institutions ${ }^{1}$, there is some concern about the breadth of knowledge and the research planning experience that graduates of such short programs may lack. With productive postdoctoral experience there may be little difference between graduates of these two systems ten years after graduation. The "fast-track" approach focuses effort early on and launches young scientists into an academic career at an earlier stage. It also lessens the risk of students becoming cheap labor for their advisors. 
It was generally agreed amongst the PODS participants that neither system was ideal and that some kind of compromise should be found.

\section{Mentorship}

To prepare any Ph.D. student for a career in research, solid mentorship is invaluable. There can be no prescribed formula for the perfect mentor: each student's needs and strengths are varied and the relationship depends on the student-mentor personality combination. The mentor has the potential to contribute greatly to all aspects of student development by demonstrating good research practices; facilitating teaching experience, cruise opportunities and international exchange; and helping to improve oral and written communication skills.

In the "fast-track" Ph.D. program, students have less time to discover protocols, people, and research techniques for themselves and so initially a fine line somewhere between total direction and gentle guidance (while hopefully ruling out complete neglect!) is required. Furthermore, there is insufficient time in such a program for a student to propose their own research question, and so the advisor must provide a preliminary, well-posed, but flexible research proposal for each new student. This situation is viewed as neither good nor bad provided that the student is aware of the issue and seeks to gain the experience they lack in a postdoctoral position.

Input from other senior scientists is also important. In combination with effective mentoring and prompt feedback from an advisor, committee meetings and departmental progress checks every 6 months can provide sufficient scientific input and motivation to keep the student focused, without prescribing their research path.

The advisor-student relationship largely shapes the quality of the Ph.D. experience for both the student and the advisor, but the student has the most to gain from a fruitful interaction (McManus, 2002a).

\section{Components of a Model Program}

Physical oceanography encompasses a wide range of techniques including theoretical investigation, numerical modeling, laboratory and field experiments. These all have a role to play in understanding ocean physics. Existing graduate programs, particularly the "fast-track" programs identified above, whilst sometimes emphasizing the interdisciplinary nature of oceanography as a whole, do not usually take an intradisciplinary approach. A physical oceanography graduate program will succeed in creating wellrounded researchers if substantial exposure is given to a range of these techniques and approaches. Students should be encouraged to combine several in a thesis project (the advisor has a role to play in ensuring that this is done sensibly) to avoid the specialization and pigeon-holing that sometimes occurs. Graduates with experience in fieldwork, numerical modeling and dynamical theory will be much more versatile in their future career. Versatility may become increasingly important in the future if physical oceanographers are to be nimble enough to take advantage of a variety of funding opportunities.

Young scientists also need to learn how to interact with other scientists and to communicate the relevance of their work to both specialists and the general public.

A comprehensive education should therefore include field work, course work, internal workshops, development of oral communication skills, teaching experience, integration into the scientific community, scientific writing and international exchange, whilst allowing time for personal and social development too. These components of a model program are discussed below.

Field work, for some of the PODS I delegates, was the most fulfilling and exciting part of their graduate experience. At some institutions the value of field work is already recognized at an institutional level, and experience at sea is an explicit requirement for obtaining a Ph.D.. Involvement in the process of designing, planning, conducting, analyzing and writing up a field experiment gives an appreciation of the difficulties to be overcome and the compromises to be made. Dealing with the challenges of observational data also provides a useful sense of perspective for those whose primary focus is on theoretical issues or numerical modeling. Most field projects require considerable scientific and logistical planning, people skills (and more people skills!), technical ability and budget management. These valuable skills are readily transferable to other endeavors in academia, government, or industry. Adding a substantial field component to Ph.D. programs will certainly increase the length of time needed to graduate, but one month on a cruise, or involved in other field work (not necessarily related to the student's own thesis), is easily achieved and the student will benefit enormously.

Course work provides a deeper understanding of theoretical concepts such as geophysical fluid dynamics, introduces necessary tools (e.g., mathematical techniques and numerical modeling) and gives a broader insight into physical oceanography and the wider field. It is hard to generalize requirements given the differences in background between physical oceanography students around the world. In the U.S., where the majority of students entering graduate programs in oceanography have had little or no previous coursework in the subject (Pedlosky, 1992), two years of classes are standard, followed by a series of qualifying exams. This shifts the emphasis away from research over the first two years, but allows for the possibility of leaving with a Masters after that if a student wishes (not possible in most non-U.S. institutions). At the opposite end of the 
spectrum, some Ph.D. programs have no coursework requirement at all.

There has been much debate concerning the balance between specialization and breadth of knowledge in a field so intricately linked to other disciplines as physical oceanography. Both Pedlosky (1992) and Farrington (2001) recognize that the vast amount of material known about the four traditional ocean science disciplines today, as well as the mathematics and physics which underpin physical oceanography, make it virtually impossible to give physical oceanography graduate students a comprehensive training in the field of ocean sciences. As Pedlosky (1992) notes, graduates should be taught to "live with a certain incompleteness" in their formal preparation. Gaps in a graduate's knowledge are inevitable, and the emphasis instead should be on learning to be an effective researcher. The acquisition of knowledge does not end upon finishing graduate school!

One suggestion to enhance breadth, whilst keeping the volume of course work down (Farrington, 2001), is to emphasize the inter-disciplinary (rather than multidisciplinary) nature of the field. An integrated course which includes lectures on diverse subjects applied to a specific problem or topic (such as estuaries) may allow students to gain enough familiarity with each subject's language and paradigms to confidently find out more in the future, when they need to.

Pedlosky (1992) suggests that the principal goal of an educator is "the development of the creative scientist rather than the simply well informed student". With this in mind, and since it represents only one part of a Ph.D. program, we suggest that limiting coursework to about one year seems to be a sensible compromise. However, a great deal of flexibility is required here. A balance between specialization and breadth of knowledge is hard to achieve and the emphasis should be on the individual needs of each student, with the option of taking further courses if desired.

Summer schools or workshops can provide techniques useful throughout a research career if they are set up to train the participants to interact on a common project relevant to their field of research. One example is the successful two-week Geophysical and Environmental Fluid Dynamics summer school, which is held annually at Cambridge University in the UK. This comprehensive program brings international students together for a wide range of courses, seminars, lab problems, computer practicals and discussion. It develops communication skills, gives presentation experience, and leads to better integration into the scientific community through the creation of ties with other students and future colleagues.

Developing communication skills, both oral and written, is essential for a career in physical oceanography. Oral communication skills can be improved by requiring Ph.D. students to give regular (at least annual) presentations to a broad oceanographic audi- ence within their home institution. This also provides an opportunity for feedback from outside of the student's usually small research group. Furthermore, a student with several presentations under their belt will have gained valuable experience prior to the thesis defense. In addition, more informal, studentorganized seminars provide opportunities to practice presenting work, and promote scientific dialogue among students without the threat of senior scientists criticizing or dominating the discussion. Weekly research group meetings during which each student has an opportunity to give an update on their progress are also invaluable-these refine ideas early on and develop the communication skills of everyone in the group.

Effective scientific writing becomes more critical the further into a research career one progresses. Despite the writing experience gained whilst a student, most postdocs still have to learn the technical details of how to approach funding agencies, prepare proposals, review papers effectively, and manage the diversity of a scientific work load.

Teaching experience is valuable in many regards. Not only does it require a thorough understanding of the subject, but it also enhances communication skills through the presentation of often complex material to an unfamiliar audience. Since most permanent academic positions involve substantial teaching commitments, early exposure to teaching will help in securing such a position later.

Integration into the scientific community is crucial for the academic exposure of a young scientist, particularly in the later stages of a Ph.D. This is most easily accomplished through attendance at national and international conferences. Some of the benefits of this exposure are obvious: support, advice, feedback, and affirmation that you are on the right track. However, networking with peers and more established scientists in academia, government, and industry becomes even more important when it is time to look for either a postdoctoral or permanent position. Establishing personal contacts is especially vital for "fast-track" Ph.D. students, who have less time to establish a publication record. It can be greatly facilitated by a supportive advisor who encourages interaction with other scientists and provides introductions at meetings.

International exchange will become increasingly important as physical oceanography moves into an age of bigger collaborative projects. Many students spend years in the relative isolation of their advisor's group, learning primarily from other members of the group. The perspective of another research environment develops a broader view, creates ties, and affirms the student's confidence to work with others outside the group. The student returns a more mature scientist with an increased awareness of research techniques and protocols, which benefits both the advisor and the student. For example, the National Science 
Foundation in the U.S. has a program that funds a summer of research at a foreign institution (see http://www.nsf.gov/sbe/int/int_gradstud.htm). Opportunities also often arise through personal connections of an advisor.

A social life, or more colloquially "having a life", is tremendously important! Students moving to a new location for their studies rely to a great extent on a functioning social group in their institution to help them get settled, and to provide the continuing support that they need. This can be fostered through organized departmental social events and the adoption of a "buddy" system for new arrivals. A balanced social and academic life for graduate students, postdocs and others should be encouraged, not least because happy people are more productive.

The challenge facing physical oceanography graduate programs is to incorporate all of these elements, whilst keeping the length of time required to graduate down.

\section{Recommendations}

This paper represents a combination of the authors' and others' experiences, based on discussion with participants at the first Physical Oceanography Dissertation Symposium. We recognize that the character and ability of an individual largely determines their success in a Ph.D. program. However, we also identify key elements and skills which we consider to be essential in a graduate education. To enhance the quality of future Ph.D. graduates we propose an international standard to which all graduate programs in physical oceanography should aspire.

Balancing the need for specialization and focus on a particular topic against the acquisition of a breadth of knowledge is not easy. In the light of the limited funding available in some countries we suggest a model four year degree structure. The first year should consist of pertinent coursework, with an interdisciplinary course and courses in other branches of oceanography (biological, chemical, geological) reserved for optional coursework early in the second year. Some flexibility is required here, with courses tailored to the individual student's needs. The focus in years two, three and four should be on research, with some exposure to teaching and participation in a summer school or workshop. Six months should be spent undertaking research at a foreign institution (probably most useful in year 3). Additionally we suggest that at least one month at sea (or involved in other field work) would broaden the student's perspective on physical oceanography. Opportunities to present research locally and at international meetings improve the student's presentation skills and provide important networking opportunities, especially in the final stages. Last, but certainly not least, we note that a balance between a social and academic life is important but often neglected.

\section{Acknowledgements}

We are grateful for the support of Walter and Judith Munk, Terri Paluskiewicz, Bill Wiseman, Chet Koblinsky, Steve Murray and Al Osborne who were kind enough to share their knowledge and offer words of wisdom and support at the 2002 Physical Oceanography Dissertation Symposium. Thanks also to Beverley Hale and Jacqueline Whelan of the American Institute of Biological Sciences for ensuring that the meeting ran smoothly, and to all the other participants at the symposium for their insightful discussions throughout the week. The meeting was supported by grants from the National Science Foundation and the Office of Naval Research. We would also like to thank the Scripps Institution of Oceanography Graduate Department for providing the statistics presented in Table 1. Discussions with Harry Bryden, Chris Garrett, Peter Killworth, Jim McWilliams and Jason Middleton were helpful during the preparation of this manuscript. Finally, we are grateful to John Farrington and Dean McManus for their thoughtful reviews and valuable suggestions.

\section{References}

Farrington, J. W., 2001: Sverdrup, Johnson and Fleming's The Oceans Revisited: What of the future of graduate education in ocean sciences? Oceanography, 14, 34-39.

McManus, D. A., 2002a: Are Ph.D. students able to explore career paths that their advisors disparage? Oceanography, 15(1), 142-143.

McManus, D. A., 2002b: When will you speak out for ocean sciences education? Oceanography, 15(4), $42-43$.

Nowell, A. R. M., 2000: Education in Oceanography: History Purpose and Prognosis. In: 50 Years of Ocean Discovery, National Science Foundation 1950-2000. National Academy Press, Washington D.C., pp 195-200.

Nyquist, J. D., 2002: The Ph.D.: a tapestry of change for the 21st century. Change, 34(6), 12-20.

OECD, 2001: Knowledge and Skills for Life: First Results from the OECD Programme for International Student Assessment (PISA) 2000, Organization for Economic Co-opertion and Development, Paris, 322pp., http:/ /www.pisa.oecd.org.

Pedlosky, J., 1992: Graduate Education in Physical Oceanography. Oceanography, 5, 117-120.

Schoedinger, S. E., 1998: Alumni Survey: A Closer Look at U.S. Marine Science and Policy Programs. Consortium for Oceanographic Research and Education, Washington, D.C., 144 pp.

Schoedinger, S., and Gordon, S., 2002: Recent statistics on US research and education in ocean sciences. Eos Transactions, AGU, 83(47), Fall Meeting Suppl., Abstract OS71E-11 (data provided by personal communication). 